\title{
Patrimonio, dinero y saber en un colectivo de mineros artesanales en la Sierra de Catorce, San Luis Potosí
}

\author{
IRENE MARÍA ÁLVAREZ RODRÍGUEZ
}

El objetivo de este texto es analizar cómo un grupo de gambusinos o mineros artesanales aseguran la supervivencia de su identidad social. Para llevar a cabo este propósito, recurro al concepto de patrimonio, al que entiendo como un tipo de relación social que vincula la continuidad de un colectivo a la reproducción de ciertos conocimientos y recursos monetarios.

PALABRAS CLAVE: patrimonio, minería, conocimientos, técnicas, dinero

Heritage, Money and Knowledge among a Group of Miners in Sierra de Catorce, San Luis Potosí

The objective of this text is to analyze how a group of artisan miners ensure their social identity survival. I appeal to the concept of heritage, which I understand as a kind of social relation that connects the continuity of a collectivity with the reproduction of knowledge and money.

KEYWORDS: heritage, mining, knowledge, techniques, money 
éstor García Canclini ha indicado que la producción cultural de los obreros tiene una memoria corta: los procesos de acumulación de saberes y técnicas están inscritos en una temporalidad limitada, casi nunca se archivan ni se documentan por medio de la escritura o la fotografía (1999: 19). De ser así, ¿cómo preserva sus legados y establece continuidades este tipo de trabajadores? En este artículo destaco la manera en que un grupo de mineros perpetúa los conocimientos técnicos de su labor al transmitirlos entre generaciones. Al mismo tiempo, muestro que el dinero asociado a la minería enfrenta restricciones en su circulación, pues se destina a la reproducción social del colectivo minero. Considero, pues, que el mantenimiento de la identidad social minera se asocia a la continuidad de ciertas técnicas, saberes y recursos.

Analizo la relación que los mineros establecen en sus contextos de trabajo, constituida por conocimientos transmitidos entre generaciones por la línea masculina. Los procesos de aprendizaje del oficio apelan a una tradición minera; el uso del cuerpo se reitera a partir de las enseñanzas de padres a hijos, o en su defecto, de mentores a aprendices. Utilizo el concepto de patrimonio para destacar que el mantenimiento de ciertas prácticas colectivas, que se sustentan en referentes temporales pretéritos e intergeneracionales, son fundamentales para preservar el oficio.

Más que entender el patrimonio como una serie de objetos o territorios valiosos per se, me preocupa la cualidad reproductiva que se asigna a ciertas acciones (Munn, 1977). Según Elizabeth Ferry y su investigación sobre el trabajo minero en el estado de Guanajuato, México, puede decirse que la característica de los bienes patrimoniales es que su intercambio se restringe a los miembros de un mismo linaje, grupo o comunidad. ${ }^{1}$ Ferry define los bienes patrimoniales como aquellos cuyo control se restringe a los miembros de un grupo, a menudo emparentado por línea paterna, que se legan de generación en generación y que poseen características afectivas fundamentales para asegurar la continuidad del colectivo. Así, la reproducción de técnicas y conocimientos propios de esta actividad productiva entre varones con antepasados

1 Por ejemplo, la legislación mexicana establece que los objetos del periodo precortesiano no pueden intercambiarse bajo ninguna circunstancia (Rozental, 2017). 
mineros puede analizarse desde la noción de patrimonio. En su sentido etimológico, el término patrimonio - derivado del latín patrimonium - se refiere a la propiedad, en este caso inmaterial, que los padres dejan a sus hijos (2011: 36, 37).

Como ha señalado Lisa Breglia, el patrimonio no es sólo un legado paterno, sino que debe entenderse como una articulación compleja entre familia y trabajo, o si retomamos su metáfora, entre sangre y sudor. Su análisis sobre la zona arqueológica de Chichen Itzá, en el estado mexicano de Yucatán, le permite mostrar cómo el acceso a los bienes que se definen como patrimonio familiar se asocian a factores como la consanguinidad, pero también al esfuerzo y la disciplina (2006: 117). ${ }^{2}$ En esa lógica, me propongo analizar las relaciones entre el oficio de minero y la pertenencia a un colectivo, así como la aplicación efectiva de una memoria social ${ }^{3}$ constituida por el saber práctico de generaciones de mineros. ${ }^{4}$

Considero que, si bien los conocimientos colectivos son esenciales para afianzar la identidad social de un grupo de trabajadores, es vital rastrear la producción de derechos y obligaciones que se crean en relación con los recursos mineros y su aprovechamiento. Esto quiere decir que no sólo me concentro en el acervo de saberes transmitidos de generación en generación, sino también en cómo se establece una serie de normas en torno a la explotación del mineral, además de hacer hincapié en los patrones de circulación del dinero que facilitan la preservación de una identidad social minera.

El concepto de economía moral (Scott, 1976) pone de relieve cómo las actividades económicas, la minería en este caso, están permeadas por normas culturales y valores. La noción subraya las consideraciones morales en torno a ciertos recursos, como las estrategias "correctas" de aprovechamiento de la mina y de gasto del dinero producido por este trabajo (Ferry, 2011; Mette, 2013; Walsh, 2003; Werthmann, 2003). En concreto, me interesa indagar en las estructuras normativas desarrolladas alrededor de una actividad, en principio, económica. Mi hipótesis es que esta moralidad resguarda tanto la continuidad del espacio minero ${ }^{5}$ como al colectivo mismo de trabajadores subterráneos. En ese sentido, por medio del seguimiento de un código normativo minero puedo observar la membresía de una comunidad moral de trabajadores de las profundidades.

Al mismo tiempo, de acuerdo con la tradición antropológica que observa las apropiaciones simbólicas del dinero (Parry y Bloch, 1989) y la literatura sobre los cursos o trayectorias de circulación del medio de cambio (Eiss, 2002; Ferry, 2011; Gilbert, 2005; Webb, 2001), me propongo analizar cómo las formas en que el dinero circula están determinadas por un objetivo primordial: la reproducción de la identidad social minera. Considero que el dinero producido en ciertos espacios laborales se somete a un régimen moral que influye en los modos en que el medio de cambio se gasta y circula. Por lo tanto, me interesa averiguar cómo contribuye el dinero a la continuidad del colectivo que lo produce.

Como ha señalado Georg Simmel, en la Edad Media existía una relación estrecha entre la personalidad y la cosa o entre la persona y la propiedad (2010: 2). ${ }^{6}$ Más tarde, la economía monetaria interrumpió la

2

Breglia (2006) muestra cómo la constitución de las ruinas en zona arqueológica se lleva a cabo por la intervención estatal, por organismos internacionales, como la Organización de las Naciones Unidas para la Educación, la Ciencia y la Cultura (UNESCO, por sus siglas en inglés), y por instancias federales, como el Instituto Nacional de Antropología e Historia (INAH), pero también por la gente que trabaja en esos espacios que devienen patrimoniales. Thomas Abercrombie (1998) recupera el concepto de memoria social, acuñado por Halbwachs, para referirse al proceso en el cual los sujetos se sitúan dentro de un horizonte histórico y establecen formas de perpetuación de la identidad ante la movilidad o el cambio.

4 Sólo pude rastrear la actividad productiva en tres generaciones.

5 Es decir, el cuidado del patrimonio minero asegura que la mina no se agote demasiado rápido o colapse. 
correspondencia entre propiedad y propietario al hacer del dinero una mediación objetiva entre persona y cosa, y transformó los intercambios económicos en procesos altamente despersonalizados. Sin embargo, incluso en el tiempo presente, "no todos los objetos del tráfico económico tienen dimensiones expresables en dinero" (Simmel, 2010: 8). En la economía moderna existen aún ciertas posesiones que nos permiten definir quiénes somos en un sentido histórico (Weiner, 1985: 33), por lo tanto, tienen un valor que supera por mucho al puramente monetario.

Ferry (2011) describe las expectativas acerca de la trayectoria del dinero producido por el trabajo minero en Santa Rosa, Guanajuato, una de las poblaciones habitadas por los empleados de la Cooperativa Minera Santa Fe. La gente esperaba que el dinero generado por la extracción de plata se invirtiera en casas particulares, edificios públicos y sagrados, de carácter colectivo, o en el bienestar de la descendencia (2011: 248-249). Es decir, la plata salía de la cooperativa y de algún modo tenía que retornar a ella. A Ferry le interesa observar cómo los mineros y sus familias imponen una trayectoria específica a la producción, circulación y consumo de la plata, así como a los salarios y ganancias asociados a su explotación.

Inspirada por ese análisis, en este trabajo examino el desarrollo de las expectativas morales de un grupo de mineros sobre la disposición correcta de los recursos financieros derivados de la minería y quiénes pueden beneficiarse de éstos. En el caso de los minerales, considero que hay cierta correspondencia entre lo que Simmel (2010) denominaba "la personalidad y la cosa", es decir, entre el producto extraído del subsuelo y el colectivo minero. En consecuencia, expongo que la construcción de la expectativa supone que el dinero producido por la venta del mineral debe retornar a su lugar de origen para ser invertido en la unidad doméstica, espacio de reproducción de la familia, y por lo tanto, de la fuerza de trabajo minera.
En suma, este texto se centra en la articulación entre conocimiento e identidad social entre un grupo de mineros. La meta es observar cómo los mineros producen patrimonio, es decir, conservan y transmiten ciertos saberes prácticos y recursos para asegurar la continuidad e identidad social de un colectivo. Mi caso de estudio se refiere al trabajo extractivo de un grupo que explota una mina ubicada en la Sierra de Catorce, una formación montañosa en la zona norte del estado mexicano de San Luis Potosí.

\section{El contexto sociohistórico y político de la Sierra de Catorce}

La región de la Sierra de Catorce se localiza al Sureste del Desierto Chihuahuense, en el Norte del estado de San Luis Potosí, próxima a Zacatecas y Nuevo León (véase el mapa 1). Es un pequeño subconjunto de montañas, de unos $40 \mathrm{~km}$ de longitud por $35 \mathrm{~km}$ de anchura. Algunas de sus cumbres superan los 3000 msnm (Giménez y González, 2011). Es un importante reducto de flora y fauna amenazada, así como una zona rica en minerales metálicos y no metálicos. El subsuelo alberga depósitos de oro, plata, cobre, plomo, zinc, hierro, antimonio y mercurio.

El primer asentamiento fue el legendario pueblo de Real de Catorce, fundado a finales del siglo XVIII tras el hallazgo de magníficas vetas de plata. Desde entonces, el destino de la región ha estado ligado a la minería. Alexander von Humboldt destacó que los

6

Aunque Annette Weiner (1992) hizo su trabajo etnográfico entre los maorí de Polinesia, presenta casos de propiedades inalienables en la tradición occidental. Señala que en la Edad Media, una vez que la línea hereditaria de transmisión de bienes se interrumpía, la compra de tierras sólo podía realizarse entre parientes: el terreno no era susceptible de ser enajenado por cualquiera. 
MAPA 1. LA SIERRA DE CATORCE

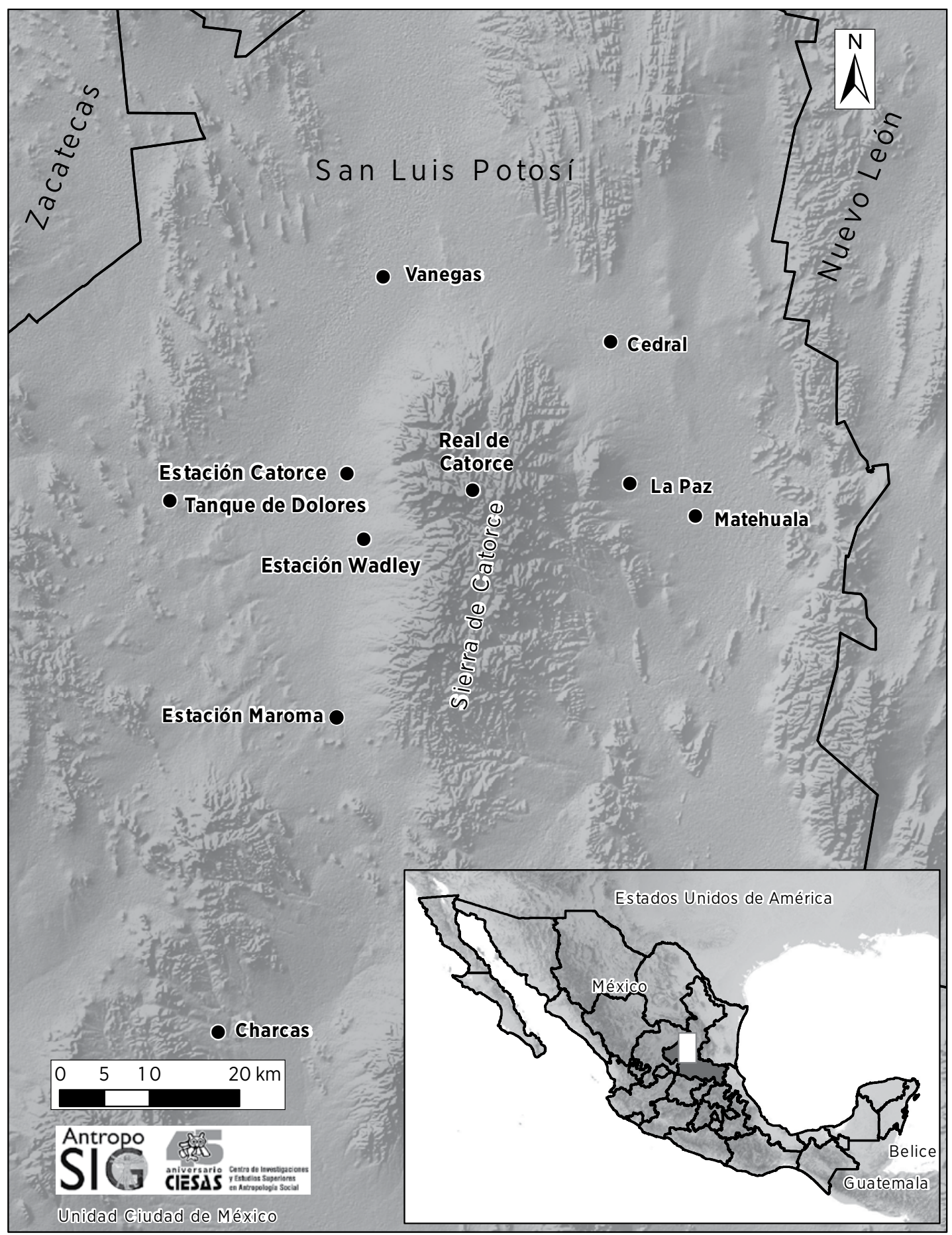

Elaboración: Bulmaro Sánchez Sandoval. 
“distritos de minas [de] Guanajuato, Zacatecas y Catorce [...] dan casi la mitad de todo el oro y plata que anualmente se ha sacado de Nueva-España" (1827: 325). ${ }^{7}$ Algunas de las minas más importantes cerraron hacia finales del siglo $\mathrm{XX},{ }^{8}$ en gran medida, por la abrupta caída del precio de la plata. Esto provocó un éxodo masivo de pobladores a otros centros mineros del Norte de México (Gámez, 2014).

Los que permanecieron en la Sierra de Catorce se dedicaron a ofertar servicios al creciente número de turistas y peregrinos católicos que cada año visita Real de Catorce, la localidad más importante de la zona. ${ }^{9}$ Otros se refugiaron en las montañas y cuidan de sus animales, huertos y cosechas. Algunos más se emplearon como trabajadores en los invernaderos de chile y jitomate que han comenzado a surgir en el área. La monotonía rural se interrumpió cuando la minería apareció de nuevo como amenaza y promesa. Motivada por el incremento en los precios de la plata, en 2009, la compañía minera First Majestic Silver Corp. manifestó su interés en explotar las vetas de plata de la vieja mina de Santa Ana, a pocos kilómetros de Real de Catorce.

Aunque muchos vieron el interés de First Majestic con buenos ojos - después de todo, los habitantes de la Sierra de Catorce tienen una biografía, historia y genealogía ligadas a la minería-, para otro sector la extracción de metálicos se percibía como una amenaza. Por lo menos desde el siglo XVIII, los huicholes han peregrinado a varios puntos de la Sierra de Catorce, pues forma parte del territorio ritual de Wirikuta. ${ }^{10}$ Provenientes del Gran Nayar - un complejo cultural que contempla una parte del estado de Nayarit y las zonas contiguas de Jalisco, Durango y Zacatecas-, los representantes de cada tukipa, o centro ceremonial huichol, hacen el viaje ritual de forma autónoma, dejan ofrendas en varios puntos y "cazan" la cactácea con propiedades alucinógenas conocida como peyote.

El otorgamiento de concesiones mineras desató un movimiento social integrado tanto por huicholes como por mestizos que cuestionan la legitimidad de las actividades extractivas dentro del Área Natural Protegida (ANP) de Wirikuta. ${ }^{11}$ Aunque el plan de manejo del ANP tolera las actividades de minería en las zonas de amortiguamiento, después de una conocida polémica que alcanzó sus puntos álgidos entre 2011 y 2013, el Consejo Regional Wixarika - una organización conformada por las autoridades tradicionales, agrarias y civiles de varias comunidades huicholas - interpuso un juicio de amparo para suspender todas las concesiones dentro del ANP.

A pesar de las controversias, la gente de la Sierra de Catorce ha seguido realizando esta actividad. Desde hace siglos, los habitantes de la región han desarrollado estrategias para sobrevivir en tiempos de adversidad, como el gambusinaje o la pequeña minería, que consiste en extraer minerales con técnicas artesanales. Un viejo minero de la ranchería de Potrero, cerca de Real de Catorce, relató cómo había sobrevivido en las décadas de 1950 y 1960 gracias a la extracción artesanal de plata, antimonio y mercurio: "mientras haya comprador, la gente va a sacar el mineral" (entrevista, Potrero, 10 de julio de 2014). En fechas recientes, el gambusinaje ha permitido

7 En la actualidad, la Sierra de Catorce está constituida por los municipios de Catorce, Cedral, Charcas, Matehuala, Vanegas, Villa de la Paz y Villa de Guadalupe.

8 Con excepción de las minas de la empresa Negociación Minera Santa María de la Paz y Anexas (Nemisa), en el municipio de Villa de la Paz, a 8 km de la ciudad de Matehuala, dedicadas a la extracción de cobre, que han funcionado sin interrupción desde finales del siglo XVIII.

$9 \quad$ En Real de Catorce se localiza el santuario católico en el que se rinde culto a la imagen de san Francisco de Asís (Álvarez, 2014).

10 De acuerdo con Arturo Gutiérrez, la primera referencia a la peregrinación huichola aparece en el informe de 1792 de don Félix Calleja. Aunque no asistió al viaje, señala que huicholes y tarahumaras se reunían en Chalchihuites, hoy en el estado de Zacatecas, donde los huicholes ubican la "primera puerta" a Wirikuta (2014: 125).

$11 \quad$ El ANP es producto de un decreto de carácter estatal y está constituida por 140211.85 ha. 
que un sector de la población de la Sierra de Catorce haga frente a los desafíos derivados de la suspensión de las actividades.

Si los ingresos brutos derivados de la venta del producto mineral no rebasan los 5000 salarios mínimos al año, de acuerdo con el estándar vigente en la Ciudad de México, o si se extraen hasta 15000 t de producto mineral para el proceso de beneficio o refinamiento, la actividad productiva se considera gambusinaje o pequeña minería (Presidencia de la República, 1992). Muchas minas entran en esta categoría y son legales. En el caso de la Sierra de Catorce, la extracción es ilegal sólo si los yacimientos están dentro del ANP.

Como he mencionado, la producción minera de la Sierra de Catorce se ha convertido en una labor problemática desde un punto de vista político, moral y legal. Por eso las actividades de extracción que se llevan a cabo en el perímetro del ANP son clandestinas. No proporcionaré información que pueda derivar en la identificación del lugar de trabajo de más de una centena de mineros artesanales. Los datos relativos a la ubicación geográfica de la mina, el tipo de mineral extraído y los nombres de los trabajadores involucrados han sido cambiados.

\section{Convertirse en gambusino}

Durante la realización de la etnografía que sustentó mi tesis doctoral (Álvarez, 2017), residentes de algunos pueblos y ranchos del distrito minero de la Sierra de Catorce narraron que las actividades de minería continuaban, aunque de modo disimulado. Después de algunos meses de investigación, conseguí una cita con el superintendente de una de las minas clandestinas que opera en las partes más recónditas de la sierra. Me recibió en su casa y tras una larga conversación accedió a mostrarme la mina. Gracias a su disposición, pude internarme decenas de veces en los túneles subterráneos a los que llamaré El Hormiguero.
Esta mina tiene varios socavones o accesos que se asoman en los reductos más altos y fríos de la sierra. El paisaje, con una densa población de pinos y formaciones geológicas caprichosas, se interrumpe por los jales ${ }^{12}$ que atraviesan de manera vertical las montañas, a modo de cascada. Algunos dicen que la profundidad de la mina alcanza los $500 \mathrm{~km} \cdot{ }^{13}$ Es difícil conocer el tamaño total de la mina debido a que el espacio es laberíntico, extenso, y muchas secciones son intransitables. De los 18 niveles que constituyen El Hormiguero, por lo menos la mitad está bloqueada por derrumbes o es tan insegura que nadie se aventura a entrar ahí.

Aunque hay una variedad de trabajadores que labora en el espacio minero, me interesa centrarme en los gambusinos o "buscones", quienes se dedican a localizar depósitos minerales y explotarlos con procedimientos rudimentarios. Los buscones son mineros independientes, es decir, trabajan en El Hormiguero pero no reciben un salario fijo, sino que venden su producción a la compañía que administra la mina, con la que negocian su valor. En agosto de 2014 había 60 gambusinos laborando en la mina. En marzo del año siguiente la cifra se había duplicado.

La mayoría de los gambusinos vive en las rancherías de la Sierra de Catorce. Para llegar a su lugar de trabajo, caminan o viajan a caballo, los más afortunados hacen trayectos de hasta dos horas en motocicleta. Para evitar estos desplazamientos, un gran número de buscones duerme en uno de los cuartos destartalados que se encuentran en la superficie, afuera de la mina. En este campamento provisional se reproduce un modo de vida altamente masculinizado. Ahí tienen lugar las actividades de

12 Depósitos de rocas molidas y minerales que se desechan después de que los recursos de interés han sido extraídos.

13 Estas dimensiones pueden ser exageradas. En realidad, ninguno de los mineros conoce la mina en su totalidad ni sabe con exactitud qué tan grande es. 
esparcimiento - muchas veces asociadas al consumo de alcohol, las apuestas y juegos de mesa-y las de descanso.

Para muchos de los trabajadores, vivir en el campamento ofrece la oportunidad de evitar desplazamientos y escapar de las obligaciones domésticas de la vivienda familiar: "en la casa uno se aburre. Aquí nos ponemos a cantar, nos emborrachamos, salimos a pasear en moto por la sierra" (entrevista con informante, El Hormiguero, 12 de febrero de 2015). En ese sentido, permanecer lejos de la familia y residir en el espacio minero incentiva la solidaridad entre los trabajadores, genera una forma colectiva de identidad laboral y socializa un modelo de masculinidad asociado al dinero, el prestigio y la capacidad física. La minería no sólo es una forma de ganarse la vida, la actividad implica dejar atrás responsabilidades y estatus relacionados con las figuras de padre o esposo para convertirse en gambusino: un trabajador que privilegia la solidaridad y el compañerismo.

Desde que las principales minas de la región suspendieron sus operaciones hace más de dos décadas, la extracción de minerales comenzó a ocupar un lugar periférico en las dinámicas económicas de la zona. Aunque no puede decirse que la minería tenga la preeminencia de antaño, para muchos originarios de la serranía este trabajo continúa siendo una realidad vigente, ya sea porque emigraron a centros mineros del Norte de México o porque su supervivencia depende de la extracción en pequeñas minas irregulares. Algunos gambusinos de El Hormiguero tienen experiencia previa, sobre todo si laboraron en los "pocitos" o minas de carbón del estado norteño de Coahuila o en Concepción del Oro, Zacatecas; para el resto, ésta es su primera incursión en el sector.

Una vez, cuando conversaba con el dueño de un hotel del poblado de Estación Wadley, en las planicies que rodean la Sierra de Catorce, señaló con desdén: "la minería se acabó con los viejos mineros.
Los jóvenes ya no saben el oficio" (entrevista, Estación Wadley, 10 de julio de 2014). La frase hacía evidente que la minería era una actividad pretérita, sólo accesible para la gente mayor y que no tenía mayor presencia entre las nuevas generaciones. Mi interlocutor agregaba que los muchachos ya no conocían el oficio y hablaba de éste como si estuviera constituido por una reserva de saberes elusivos y herméticos: ¿quién es poseedor y transmisor legítimo del conocimiento minero? ¿Cómo se llega a pertenecer a la comunidad moral de trabajadores subterráneos?

En ocasiones, dentro de la mina, los gambusinos más experimentados se acercaban para enseñarme cómo decodificar el espacio. Me decían que no prestara atención a las marcas más brillantes de la geografía subterránea, sino que me concentrara en las más discretas, pues ahí estaba el mineral. Al recorrer un segmento del interior geológico con un dedo, el gambusino se transformaba en un intérprete de la mina: me enseñaba a rastrear una veta, a seguirla durante metros, y sobre todo, a verla. Durante mis incursiones, me instruían sobre cómo discriminar entre sustancias sin valor monetario y las que sí lo tenían. Con frecuencia me decían que desconfiara de las características superficiales y engañosas de las sustancias minerales, como el color, para centrarme en aspectos como su opacidad o la disposición de los yacimientos. Me daba cuenta de que reconocer el mineral en su estado puro es un requisito fundamental para pertenecer a la comunidad moral de los gambusinos (Ferry, 2011: 248).

Afuera de la mina, los gambusinos incluso señalaban el paisaje y por las formaciones geológicas establecían qué zonas tenían potencial. A veces, durante las comidas en el exterior, los veteranos enseñaban a los más jóvenes a distinguir las venas y mantos con contenido metálico, o las elevaciones del terreno en las que suponían que había yacimientos importantes, y establecían relaciones entre cierto tipo de vegetación, o la falta de ella, y minas 


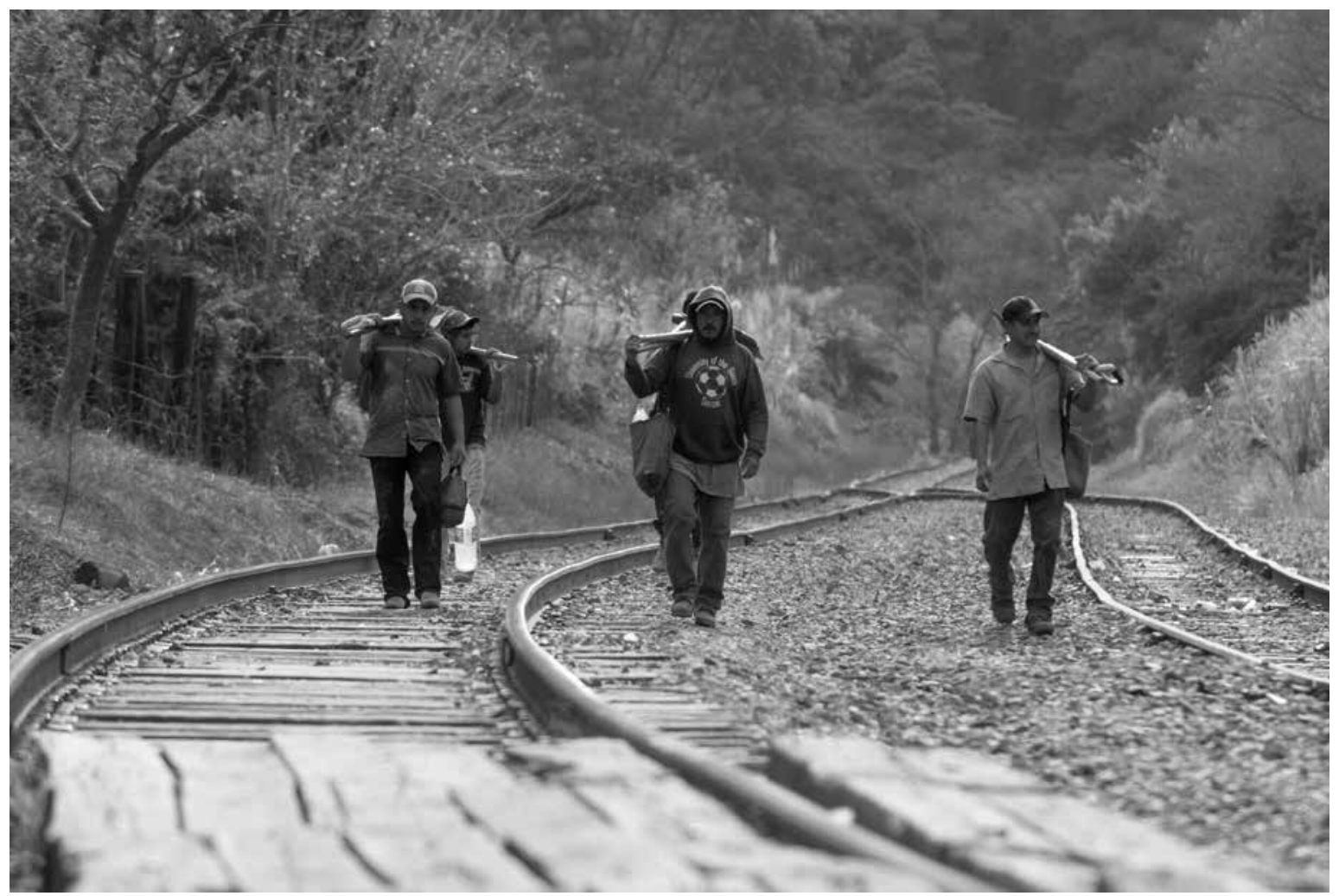

RodRIGo GonZÁLEZ • Ejidatarios vuelven a casa después de trabajar para hacer una senda turística, San Luis Potosí, marzo de 2013.

inexploradas. Ya fuera dentro o fuera de la mina, los gambusinos maduros socializaban la percepción —entendida como una forma de ver- y seguían un proceso de transmisión que iba de los más experimentados a los más inexpertos. Cuando pregunté en qué consistía ser minero, Juan, un buscón retirado, me dijo: "es sacarle lo bueno a la tierra [...], encontrarle lo valioso al cerro" (entrevista, Real de Catorce, 9 de febrero de 2015).

Muchos de los gambusinos experimentados dicen haber aprendido el oficio de sus padres. En general, se espera que ellos enseñen el oficio a sus descendientes. Un día, un hombre joven, sin experiencia en minería, llegó a El Hormiguero buscando trabajo. El responsable en turno lo reprendió: "es que no saber ser minero es tu culpa, desde chiquito te hubieras puesto a rascarle al cerro, le hubieras dicho a tu papá que te llevara" (El Hormiguero, 11 de marzo de 2015). Es común que los niños acompañen a sus padres a su lugar de trabajo desde los siete $\mathrm{u}$ ocho años de edad, o en su defecto, en los primeros años de la pubertad. En esa lógica, hay una expectativa de que el conocimiento acumulado se transmita a las generaciones siguientes y que la presencia del niño en el espacio de trabajo del progenitor establezca una continuidad entre el pasado y el futuro del oficio.

La socialización del trabajo de minero no sucede siempre en el seno familiar. En el caso del recién llegado, quien tenía que aprender con rapidez su labor, el superintendente le asignó un minero experimentado como acompañante. Unos días después le pregunté cómo era la relación de enseñanzaaprendizaje que establecía con su mentor y señaló que en realidad lo ponían a hacer tareas difíciles, 
como prender dinamita, sin explicación ni preámbulo. Se esperaba que siguiera al experto durante sus tareas cotidianas y que aprendiera el oficio mediante la observación e imitación. En muchos sentidos, esta relación de enseñanza entre el experimentado y el inexperto se asemejaba a la de padres e hijos. El conocedor es una especie de padre ficticio en el ámbito de la mina mientras el aprendiz lo acompaña y se familiariza con un saber eminentemente práctico y colectivo. A diferencia de lo que ocurre entre gambusinos emparentados, la relación entre principiante y mentor involucra una desigualdad económica, pues el primero se queda con un porcentaje mayor de las ganancias asociadas a la venta de mineral.

Si bien predomina la transmisión de conocimientos de padres a hijos, no se excluyen otras dinámicas intergeneracionales fuera de esta relación parental. Es posible ver que hermanos o primos mayores, más experimentados en el oficio, instruyan a parientes legos. Como señala Ferry, dentro del espacio minero se establece una serie de responsabilidades para asegurar la producción de mineral y al mismo tiempo reproducir el beneficio entre las nuevas generaciones de mineros. En esa lógica, se puede decir que los conocimientos del oficio están restringidos a los miembros de un grupo y se legan de generación en generación a menudo por línea masculina. Estas prácticas de transmisión del oficio son fundamentales para asegurar la continuidad del colectivo (2011: 36-37). En ese sentido, en la transmisión se reproducen poderosas asociaciones entre género, parentesco y oficio.

Además de poner énfasis en las redes de cooperación que se extienden entre los miembros de una familia, es importante observar cómo se establece una expectativa de orden normativo respecto a la explotación minera. José Luis Sariego señala que los gambusinos a menudo son acusados de ser depredadores, debido a que "tratan de reducir al mínimo los costos de operación, extrayendo sólo minerales de alta ley y recurriendo al uso de implementos y herramientas de trabajo simples" (1994: 176), lo que, supuestamente, perjudica las minas. Entre los mineros que han pasado por un proceso de profesionalización formal, los gambusinos se consideran ladrones y causantes de accidentes (Reygadas, 2010: 177), lo cual conduce a que muchos de ellos escondan su identidad laboral.

Incluso los gambusinos, que pueden ser juzgados de inmorales, mantienen una serie de expectativas normativas respecto al laborío. Durante mis incursiones etnográficas, observé una actitud crítica de los varones de mayor edad hacia los métodos extractivos de algunos, a quienes se considera egoístas porque no se preocupan por el bienestar de la mina a mediano o largo plazo. Atentan contra la mina al llevar a cabo una extracción irracional y desordenada que menoscaba el futuro del espacio minero. Desde la perspectiva de los mineros experimentados, hay una forma correcta de disponer de los recursos y se respeta la mina como entidad orgánica.

Los viejos describen la mina como bonita y noble. Juan, el buscón retirado, que ahora administra un hotel en Real de Catorce, sintetizó la visión de muchos mineros independientes sobre sus espacios de trabajo: "una mina viene siendo como una criatura que nace y le das principios, sabe por dónde camina, si no les das buenos principios, se desbarrancó la criatura y nos llevó a todos entre las patas" (entrevista, Real de Catorce, 9 de febrero de 2015). Hace explícito que para los gambusinos de mayor edad la mina es un patrimonio que debe ser cuidado por los buscones. Al establecer la analogía entre el complejo subterráneo y un recién nacido, destaca que la mina es una responsabilidad y se establece la necesidad de que cumpla un ciclo vital, es decir, que se agote al llegar a una edad madura y no antes. También expresa que, si la mina colapsa, con ella lo hacen los mineros. En ese sentido, la mina es esencial para asegurar la continuidad del colectivo de los gambusinos, a cambio, éstos tienen la obligación de cuidarla y legarla a las generaciones futuras. 
El trabajo de minero puede verse desde una perspectiva que subraya su cualidad reproductiva, aunque es preciso reconocer que existen intereses colectivos, hay espacios de lucha, conflicto e individuación. Algunos de los mineros más jóvenes mantienen una relación deliberadamente utilitaria con el espacio minero, lo cual violenta el código moral de los veteranos. Un sector importante de los buscones está conformado por adultos jóvenes, padres de familia que alternan el trabajo de minero con otros modos de sustento, como la agricultura o la compraventa de gallos de pelea o ganado. Quizá por eso algunos de los muchachos no parecen querer adscribirse a la comunidad moral de los gambusinos. Ramón, uno de los mineros más exitosos de El Hormiguero, afirma: "yo no me voy a dedicar de lleno a ser buscón, yo soy gallero y campesino, nomás que cuando necesito dinero voy a la mina, trabajo un rato pa' sacar una feria y ya" (entrevista, San José de Coronados, 21 de marzo de 2015). El testimonio revela una distancia respecto al oficio, además de exponer una visión monetarista - es decir, no patrimonial - sobre el trabajo extractivo y sus cartografías subterráneas. En última instancia, el alejamiento, no reconocerse como gambusino, es una manera de rechazar las obligaciones asociadas a la sangre y el sudor, es decir, a la familia y el trabajo.

\section{Las cuadrillas como forma de organización del trabajo}

Una manera de compensar las asimetrías en el conocimiento del oficio, la capacidad y el vigor físico de los mineros, es organizar cuadrillas o grupos de trabajo. Por lo regular, los colectivos tienen entre tres y cinco miembros, y casi siempre comparten apellido. Se recurre al nombre familiar para referirse a una cuadrilla, por ejemplo, los Valdés. ${ }^{14}$ En casos extraordinarios, los grupos constan sólo de padre e hijo, o en su defecto, de mentor y aprendiz. En el espacio subterráneo, los más experimentados efectúan las labores de reconocimiento del mineral e indican a sus discípulos cuál es la mejor técnica para extraer los depósitos metálicos. Como sostiene Eduardo Flores (1986), las cuadrillas facilitan la capacitación, pues la experiencia de trabajo acumulada se distribuye de la punta y hacia la base.$^{15}$ En ese sentido, los veteranos son los cabezas de cuadrilla, mientras el resto suple su falta de conocimiento con fuerza de trabajo.

Durante el proceso de exploración y explotación de un depósito mineral, los miembros de la cuadrilla colaboran al enseñar a los más jóvenes a detectar los yacimientos en las profundidades y les muestran cómo extraer la mayor cantidad de mineral con la menor cantidad de esfuerzo posible. Los más inexpertos compensan su falta de conocimiento con rendimiento físico, transportan grandes costales de carga en la espalda o taladran las paredes rocosas de la mina bajo la mirada atenta de los viejos. Por ejemplo, la cuadrilla de los Ramírez está constituida por Anselmo, de 65 años de edad, y por sus hijos, de 32 y 36 años, respectivamente. El padre efectúa las labores de reconocimiento y establece la estrategia de extracción más adecuada, y los hijos siguen sus instrucciones.

Cada sábado, los gambusinos acuden a la mina a cobrar el dinero que les corresponde de acuerdo con el mineral que extrajeron. En la pared exterior

14 El número de integrantes de la cuadrilla está determinado por la cantidad de varones de la familia extendida con residencia patrilocal.

15 Las cuadrillas son una forma organizativa con larga historia en la minería. Inés Cortés señala que una variedad de autores habla de la existencia de cuadrillas en lugares tan distantes como Inglaterra, Zambia o Bolivia, durante los siglos XIX y Xx (2009: 104). En el caso de México, Flores (1986) establece que fue la forma típica de organización del trabajo minero durante el siglo xIx. Según Cortés, las cuadrillas se reactivaron durante las décadas de 1970 y 1990 (2009: 111) 
de una oficina improvisada, se coloca un pedazo de cartón con los nombres de los líderes de cuadrilla, los kilos de mineral extraídos y el pago que corresponde a cada grupo. Los líderes, muchas veces los padres, distribuyen el dinero de manera equitativa entre los miembros del colectivo de trabajo. ${ }^{16}$ Los buscones se reúnen para ver el cartón que expone el desempeño semanal del colectivo al que pertenecen, comentan el éxito de los colegas más productivos y se burlan de los que obtuvieron la menor cantidad de mineral, y por lo tanto, de dinero.

La solidaridad familiar en el trabajo posibilita que se extiendan los rangos de edad aptos para emplearse como gambusino. En una ocasión, platicaba con un buscón acerca de un anciano que obtenía menos de 1000 pesos por semana ${ }^{17}$ porque no podía internarse en las partes más ricas y profundas de la mina: "es que sus hijos deberían ayudarle, repartirse lo que ganan. Este trabajo es puro hombro. Es a cincel y a martillo, y el viejillo ya no aguanta. Por ahí andan otros como él, pero sus hijos les echan la mano y a éste lo dejan solo" (entrevista, Real de Maroma, 14 de febrero de 2015). En consecuencia, trabajar con familiares y dividir los ingresos obtenidos también se refiere a un tipo de economía moral (Scott, 1976) que privilegia la reciprocidad entre varones emparentados.

Puede decirse que las cuadrillas constituidas por miembros emparentados potencian la transmisión intergeneracional de conocimientos, pero también establecen una forma particular de circulación del dinero: los padres reciben el pago y lo reparten al resto de su linaje.

Esta forma de organización laboral tiene otros rendimientos. El gambusinaje es una de las estrategias para la reproducción de la unidad doméstica. Los patrones de poblamiento de la Sierra de Catorce se caracterizan tanto por la dispersión territorial como por la residencia en familias extensas bajo el patrón virilocal. Es casi una regla que los hijos casados vivan en casa del padre con sus esposas y descendencia. Las familias de los gambusinos alternan la labor campesina con la actividad minera; de esta manera, completan la producción agrícola de autoconsumo con los ingresos producidos por la extracción de mineral. Por lo regular, las mujeres se encargan de los trabajos no remunerados, como la preparación de alimentos, el mantenimiento de los huertos y el cuidado del ganado menor. Los hombres obtienen dinero con su trabajo en la mina y realizan actividades agrícolas, de caza y recolección, con fines de subsistencia o de comercialización en pequeña escala. En general, se observa que los buscones-campesinos han desarrollado una capacidad de adaptación basada en la multiocupacionalidad.

Casi siempre, los miembros de la cuadrilla comparten el espacio doméstico, por lo tanto, el dinero obtenido en el trabajo de la mina se destina al mantenimiento de la casa. En claro paralelismo con la organización del trabajo en la mina, la cabeza de la cuadrilla es el patriarca y jefe de familia. En esa lógica, el trabajo y la casa convergen en la aceptación de una jerarquía de género y generación, así como de una organización patrilocal.

Así, las cuadrillas son un tipo de unidad de producción y una forma de división social del trabajo. Si consideramos que muchos gambusinos siguen un patrón de residencia patrilocal, es notorio que este arreglo económico, pero también laboral, sustenta la reproducción del ámbito doméstico. Al casarse, los gambusinos suelen construir un cuarto en el terreno o solar de sus padres y es común que éstos ayuden a cuidar y alimentar a sus nietos. En el caso que nos compete, la organización social minera muestra paralelismos con el orden doméstico, y esto

Como se mencionó, si los miembros de la cuadrilla no están emparentados, la repartición de dinero puede no ser simétrica.

17 Una cuadrilla de gambusinos puede ganar hasta 20000 pesos por semana. 


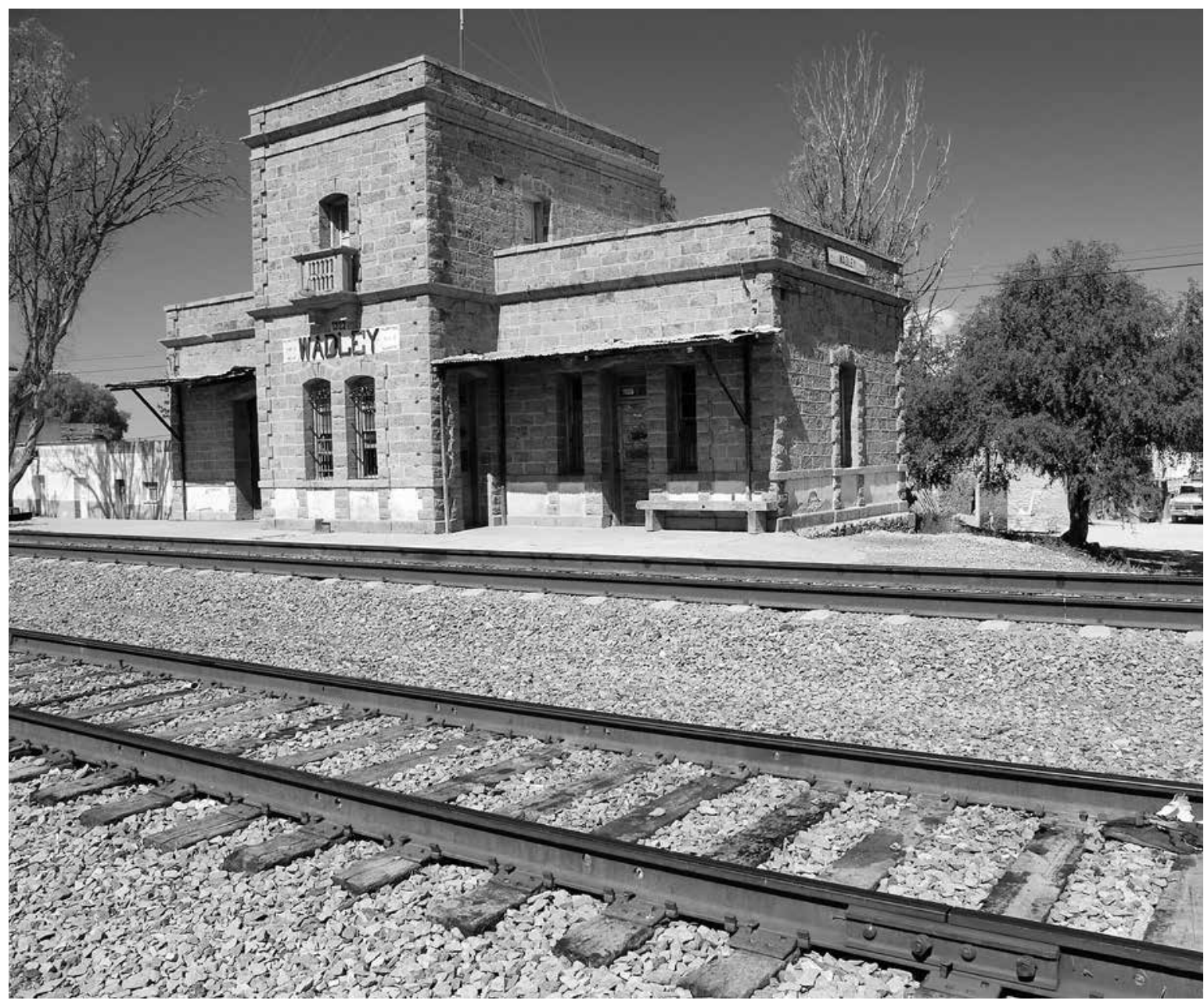

Comisión MexicAna de Filmaciones • Estación de tren en Wadley, San Luis Potosí, junio de 2005.

me lleva a aseverar que el linaje de los mineros y la continuidad de la familia extensa son interdependientes.

La semejanza entre la organización del trabajo y el orden doméstico sugiere que al hablar de "la casa" de los gambusinos nos referimos a una unidad doméstica tanto minera como campesina. Si bien todos los miembros de la unidad doméstica contribuyen al mantenimiento de la unidad productiva, la aportación del trabajo en la minería es el dinero, mientras la agricultura de subsistencia y la ganadería proveen los alimentos básicos, como frijol, queso y carne. Por supuesto, la exclusión de las mujeres del mercado de trabajo remunerado no sólo es una forma de organización laboral, sino también de la sexualidad. Como señala Thomas Miller Kublock, respecto a la mina de cobre El Teniente, en Chile, la minería es una actividad patriarcal, porque supone un tipo de control sobre el espacio de lo doméstico y lo femenino (1998: 188). En este caso, el hecho de que los varones sean los únicos con acceso a una remuneración provoca una división sexual del trabajo, en la cual las mujeres quedan excluidas de las labores lucrativas y son sometidas a un poder patriarcal que relaciona la masculinidad con el dinero. 


\section{Algunos comentarios finales}

He descrito la forma en que el oficio de minero se ha reproducido a lo largo del tiempo y me he centrado en la transmisión intergeneracional de conocimientos. Esta perspectiva me ha llevado a entender la práctica de la minería como una relación patrimonial, en la cual los trabajadores crean y se adscriben a una comunidad de gambusinos; establecen derechos de posesión y de uso sobre prácticas y conocimientos; y construyen la obligación de mantener y heredar ciertos bienes a las generaciones futuras.

De manera simultánea, muestro que la adquisición de habilidades para la minería es un proceso que sucede en la práctica. Se aprende equivocándose. El grado de educación formal no tiene relevancia para la organización laboral, las técnicas se aprenden por imitación in situ. La organización laboral por cuadrillas hace que la productividad y el aprendizaje no se asocien a un esfuerzo individual, sino familiar o grupal. La práctica y el saber colectivo diluyen diferencias de edad, capacidades físicas y conocimientos técnicos.

La organización por cuadrillas hace que el dinero producido por la venta de mineral se reparta de manera simétrica entre los miembros varones de un grupo familiar. La cuadrilla funciona como un esquema de solidaridades que asegura la supervivencia de todos sus miembros al proporcionar un incentivo económico no individual, sino colectivo. La característica más evidente de esta forma de organización del trabajo es que no hay una distinción clara entre los intereses de la familia y del colectivo minero: hay una integración entre el ámbito laboral y el doméstico. Quizá la mejor manera de ejemplificar este fenómeno es que el padre de familia es también el líder de la cuadrilla.

El gambusinaje es un oficio relacionado de modo profundo con la consanguinidad, la memoria colectiva y la tradición. Sin embargo, en algunos casos, los jóvenes rechazan el oficio de minero como un derecho que se tiene por nacimiento y por medio del trabajo, y realizan la actividad extractiva como una acción utilitaria, orientada a la obtención de un ingreso que complemente lo que reciben por trabajos con los que sí se identifican en un plano afectivo, como ser campesino o gallero. Así, es posible ver los límites de la reproducción del patrimonio entre algunos miembros de las generaciones más recientes de gambusinos. D

\section{Bibliografía}

Abercrombie, Thomas, 1998, Pathways of Memory and Power. Ethnography and History among an Andean People, The University of Wisconsin Press, Madison.

Álvarez, Irene, 2014, "Los caminos de la devoción: el culto a san Francisco de Asís", en Susana Casarín Pliego y Marcela Langrave (eds.), Real de Catorce: zona de monumentos históricos, Instituto Nacional de Antropología e Historia, México, pp. 45-51.

__, 2017, Después de Wirikuta. Patrimonio y conflicto en la Sierra de Catorce, tesis de doctorado en ciencias sociales y humanidades, Universidad Autónoma Metropolitana-Cuajimalpa, México.

Boeck, Filip de, 1998, "Domesticating Diamonds and Dollars: Expenditure, Identity and Sharing in Southwestern Zaire (1984-1997)", Development and Change, vol. 29, núm. 4, pp. 777-810.

Bourdieu, Pierre, 2000, Cosas dichas, Gedisa, Barcelona.

— 2002, Lección sobre la lección, Anagrama, Barcelona.

Brazeal, Brian, 2014, "The Fetish and the Stone: A Moral Economy of Charlatans and Thieves", en Paul Christopher Johnson (coord.), Spirited Things. The Work of "Possession" in Afro-Atlantic Religions, The University of Chicago Press, Chicago, pp. 131-154.

Breglia, Lisa, 2006, Monumental Ambivalence: The Politics of Heritage, University of Texas Press, Austin. 
Cajías, Magdalena, 2010, “Crisis, diáspora y reconstitución de la memoria histórica de los mineros bolivianos: 1986-2003", en Si Somos Americanos, vol. 10, núm. 2, pp. 61-96.

Connell, Raewyn, 1995, Masculinities, Polity Press, Cambridge.

Cortés Campos, Inés, 2009, “Economías subterráneas. Minería informal en México”, en Relaciones, vol. 30, núm. 118, pp. 97-124.

Cuvelier, Jeroen, 2011, Men, Mines and Masculinities: The Lives and Practices of Artisanal Miners in Lwambo (Katanga Province, DR Congo), tesis de doctorado en antropología social y cultural, Katholieke Universiteit Leuven, Lovaina.

D’Angelo, Lorenzo, 2014, "Who Owns the Diamonds? The Occult Economy of Diamond Mining in Sierra Leone”, en Africa, vol. 84, núm. 2, pp. 269-293.

Eiss, Paul, 2002, "Hunting for the Virgin: Meat, Money, and Memory in Tetiz, Yucatan”, en Cultural Anthropology, vol. 17, núm. 3, pp. $291-330$.

Ferry, Elizabeth, 2011, No sólo nuestro. Patrimonio, valor y colectivismo en una cooperativa guanajuatense, El Colegio de Michoacán/ Universidad Iberoamericana, Zamora.

Flores Clair, Eduardo, 1986, “Minas y mineros: pago en especie y conflictos, 1790-1880", en Historias, núm. 13, pp. 51-68.

Gámez, Moisés, 2014, Cohesión, movilizaciones y tenacidad. Trabajadores y empresas en la minería y la metalurgia potosinas, 1880-1926, El Colegio de San Luis, San Luis Potosí.

García Canclini, Néstor, 1999, “Los usos sociales del patrimonio cultural”, en Encarnación Aguilar Criado (ed.), Patrimonio etnológico. Nuevas perspectivas de estudio, Consejería de Cultura, Andalucía, pp. 16-33.

Gilbert, Emily, 2005, “Common Cents: Situating Money in Time and Place”, en Economy and Society, vol. 34, núm. 3, pp. 357-388.

Giménez de Azcárate, Joaquín y Onésimo González, 2011, "Pisos de vegetación de la Sierra de Catorce y territorios circundantes (San Luis Potosí, México)", en Acta Botánica Mexicana, núm. 94, pp. 91-123.

Grätz, Tilo, 2003, "Gold-mining and Risk Management: A Case Study from Northern Benin”, en Ethnos, vol. 68, núm. 2, pp. $192-208$.

Gutiérrez, Arturo, 2014, "Violenza e simulacro. Imprese minerarie transnazionali a Wirikuta: scenario di una tragedia nazionale", en Antrocom, vol. 10, núm. 1, pp. 121-146.

Harries, Patrick, 1994, Work, Culture, and Identity: Migrant Laborers in Mozambique and South Africa, 1860-1910, Witwatersrand University Press, Johannesburgo.

Humboldt, Alexander von, 1827, Ensayo político sobre la Nueva España, vol. 4, Imprenta de Jules Renouard, París.

Jiménez, Nora Edith, 2010, “Introducción”, en Nora Edith Jiménez (ed.), Familia y tradición: herencias tangibles e intangibles en escenarios cambiantes, El Colegio de Michoacán, Zamora, pp. 11-34.

Kublock, Thomas Miller, 1998, Contested Communities. Class, Gender and Politics in Chile's El Teniente Copper Mine, 1904-1951, Duke University Press, Durham.

Mette, M. High, 2013, "Polluted Money, Polluted Wealth: Emerging Regimes of Value in the Mongolian Gold Rush", en American Ethnologist, vol. 40, núm. 4, pp. 676-688.

Munn, Nancy, 1977, "The Spatiotemporal Transformations of Gawa Caones”, en Journal de la Société des Océanistes, vol. 33, núms. 54-55, pp. 39-53.

Nash, June, 1979, We Eat the Mines and the Mine Eats Us: Dependency and Exploitation in Bolivian Tin Mines, Columbia University Press, Nueva York.

Parry, Jonathan y Maurice Bloch, 1989, Money and the Morality of Exchange, Cambridge University Press, Cambridge.

Presidencia de la República, 1992, "Ley minera”, en Diario Oficial de la Federación, 26 de junio.

Reygadas, Pedro, 2010, Las vetas del lenguaje minero: viaje al centro del inframundo, El Colegio de San Luis, San Luis Potosí.

Rozental, Sandra, 2017, "On the Nature of Patrimonio: Cultural Property in Mexican Contexts", en Jane Anderson y Haidy Geismar (eds.), The Routledge Companion to Cultural Property, Routledge, Londres.

Salazar-Soler, Carmen, 2010, “Cuando la empresa se instala, el ‘diablo’ se muda a vivir en los socavones”, en Anthropologica, vol. 28, núm. 28, pp. 183-215

Sariego, José Luis, 1989, Enclaves y minerales en el Norte de México: historia social de los mineros de Cananea y Nueva Rosita, 1900-1970, Centro de Investigaciones y Estudios Superiores en Antropología Social, México.

, 1994, “Persistencia y estrategias de adaptación de la pequeña minería en la Sierra Madre Occidental”, en XVIII Simposio de Historia y Antropología de Sonora, vol. 2, Hermosillo, pp. 171-182. 
Scott, James, 1976, The Moral Economy of the Peasant. Rebellion and Subsistence in Southeast Asia, Yale University Press, New Haven y Londres.

Simmel, Georg, 2010, Cultura líquida y dinero. Fragmentos simmelianos de la modernidad, Universidad Autónoma Metropolitana-Cuajimalpa/ Anthropos, Barcelona.

Taussig, Michael, 1980, El diablo y el fetichismo de la mercancía en Sudamérica, Nueva Imagen, México.

Walsh, Andrew, 2003, “'Hot Money' and Daring Consumption: in a Northern Malagasy Sapphire-Mining Town”, en American Ethnologist, vol. 30, núm. 2, pp. 290-305.

Webb, Keane, 2001, "Money is No Object: Materiality, Desire, and Modernity in an Indonesian Society", en Fred R. Myers (ed.), The Empire of Things: Regimes of Value and Material Culture, School of American Research Press, Santa Fe, pp. 65-90.

Weiner, Annette, 1985, "Inalienable Wealth", en American Ethnologist, vol. 12, núm. 2, pp. 210-227.

1992, Inalienable Possessions. The Paradox of Keeping-while-Giving, University of California Press, Berkeley.

Werthmann, Katja, 2003, "Cowries, Gold and 'Bitter Money' Gold-Mining and Notions of III-Gotten Wealth in Burkina Faso”, en Paideuma, vol. 49, pp. 105-124.

\section{Entrevistas}

Buscón, acerca de un anciano, Real de Maroma, 14 de febrero de 2015.

Dueño de hotel, Estación Wadley, 10 de julio de 2014.

Informante, El Hormiguero, 12 de febrero de 2015.

Juan, buscón retirado, Real de Catorce, 9 de febrero de 2015.

Ramón, San José de Coronados, 21 de marzo de 2015.

Responsable en turno, El Hormiguero, 11 de marzo de 2015.

Viejo minero, ranchería Potrero, 10 de julio de 2014. 